\title{
Genesis of GABA-Immunoreactive Neurons in the Ferret Visual Cortex
}

\author{
Jean D. Peduzzi \\ Department of Physiological Optics, School of Optometry/The Medical Center, The University of Alabama at Birmingham, \\ Birmingham, Alabama 35294
}

\begin{abstract}
The pattern of neurogenesis of GABA-immunoreactive neurons in the ferret primary visual cortex was determined using immunohistochemical and ${ }^{3} \mathrm{H}$-thymidine autoradiographic techniques. Neurons in the visual cortex of the ferret undergo their final cell division during a period extending from embryonic day 20 (E20) to postnatal day 14 (P14) and follow an inside-out pattern of neuronal production (Jackson et al., 1984) similar to that observed in other mammals. Earliergenerated neurons are found at deeper cortical positions in the adult than are those generated later. Layer I is an exception to this rule, since neurons destined for this layer are produced at both the beginning and end of neurogenesis. In this study, the pattern of neurogenesis of GABA-immunoreactive neurons is compared to the pattern observed for nonimmunoreactive neurons. The overall pattern of cortical neurogenesis (inside-out pattern) is similar for GABA-immunoreactive neurons and neurons that are not GABA-immunoreactive. However, the GABA-immunoreactive neurons born on a given day of development are more broadly distributed across the radial axis of the adult cortex than are nonimmunoreactive neurons generated on the same day. GABA-immunoreactive neurons generated later in neurogenesis are, on average, slightly smaller than those generated early. If GABA-immunoreactive neurons in the visual cortex are interneurons, then these findings suggest that interneurons follow the same pattern of neurogenesis as do projecting neurons in the visual cortex.
\end{abstract}

Neurogenesis in the ferret visual cortex occurs during a 5 week period, which extends from embryonic day 20 (E20) to postnatal day 14 (P14), and exhibits an inside-out pattern of cell production (Jackson et al., 1984; Jackson, 1986) that is typical of that observed in other mammals. With the exception of the neurons in layer I, earlier-generated neurons lie at deeper cortical positions in the adult than those generated later. Layer I neurons in the ferret are produced at the beginning and end of neurogenesis.

In recent years, there has been tremendous interest in identifying and describing neurons that use GABA as a neurotransmitter. Three different strategies are being used in attempts to identify GABA neurons in the visual cortex. One method is the

\footnotetext{
Received April 13, 1987; revised Aug. 3, 1987; accepted Aug. 4, 1987.

I want to thank Dr. Terry L. Hickey for his help and encouragement, and Mrs. Pam Kontzen for her expert assistance. This work was supported by NIH Grants EY01338, EY03039 (CORE), and RR05807.

Correspondence should be addressed to Dr. Peduzzi at the above address.

Copyright (c) 1988 Society for Neuroscience $0270-6474 / 88 / 030920-12 \$ 02.00 / 0$
}

uptake study, in which ${ }^{3} \mathrm{H}-\mathrm{GABA}$ is injected into the cortex. GABA neurons are thought to selectively take up the ${ }^{3} \mathrm{H}-\mathrm{GABA}$ by a high-affinity system. This method has been used by a number of investigators (Hökfelt and Ljungdahl, 1972; Chronwall and Wolff, 1980; Somogyi et al., 1981; DeFelipe and Jones, 1985). However, a recent study in the monkey visual cortex suggests that some neurons that do not use GABA as a neurotransmitter may take up the ${ }^{3} \mathrm{H}-\mathrm{GABA}$ (Kisvárday et al., 1986). Another method that possibly identifies GABA neurons is the immunohistochemical demonstration of glutamate decarboxylase (GAD), which is the rate-limiting enzyme in GABA synthesis. Using this method, a heterogeneous population of nonpyramidal neurons in the visual cortex has been revealed (Ribak, 1978; Hendrickson et al., 1981; Somogyi et al., 1983). Another method is the immunohistochemical demonstration of GABA, which reveals a similar nonpyramidal population in the visual cortex (Somogyi and Hodgson, 1985; Hendry et al., 1987). All, or almost all, of the GAD-immunoreactive neurons are also GABA-immunoreactive in the cortex (Somogyi et al., 1984) and retina (Hendrickson et al., 1985). A possible advantage of examining $\mathrm{GABA}$, as opposed to $\mathrm{GAD}$, immunoreactivity is that with GABA immunoreactivity, it is not necessary to use colchicine, which may not be equally available to all neurons (Gabbott and Somogyi, 1986).

There is substantial evidence that cortical neurons using GABA as a neurotransmitter are interneurons and mediate inhibition. Undercutting the cortex does not change GABA levels (Reiffenstein and Neal, 1974; Emson and Lindvall, 1979; Ulmar and Neuhoff, 1980). Furthermore, neurons in the visual cortex that project to other areas of the brain are pyramidal neurons (Gilbert and Kelly, 1975; Lund et al., 1975; Segraves and Rosenquist, 1982), which differ in morphology from the nonpyramidal GADand GABA-immunoreactive neurons (Ribak et al., 1981; Somogyi, 1986). GABA applied iontophoretically in the cat visual cortex leads to inhibition (Krnjevíc and Schwartz, 1967; Wallingford et al., 1973), and the release of GABA is associated with inhibition (Iversen et al., 1971; Clark and Collins, 1976). A possible role of GABA neurons in the visual cortex is suggested by the fact that inhibiting GABA leads to a loss of orientation selectivity in certain neurons in the visual cortex (Rose and Blakemore, 1974; Sillito, 1979; Tsumoto et al., 1979).

It was once generally accepted that the production of projecting neurons preceded that of interneurons (for example, see Taber Pierce, 1967; Hinds, 1968; Angevine, 1970). However, this issue remains unresolved, since different areas of the brain seem to have different patterns of neurogenesis. By using newly developed methods to possibly identify GABA neurons and thereby identify interneurons, this question is again addressed. 
In the mouse hippocampus, the peak of neurogenesis of GADimmunoreactive neurons is earlier than the peak of nonimmunoreactive neurons (Soriano et al., 1986). However, there is evidence that not all GAD-immunoreactive neurons in the hippocampus are interneurons (Ribak et al., 1986). In another region of the mouse brain (somatosensory cortex), GAD-immunoreactive neurons follow the same pattern of neurogenesis as that of nonimmunoreactive neurons (Fairén et al., 1986). Wolff et al. (1978) found that GABA-accumulating neurons in the rat visual cortex do not follow the inside-out spatiotemporal pattern, and that GABA-accumulating neurons destined for all of the cortical layers are produced during most of neurogenesis. A recent study of neurogenesis by Miller (1985) suggests that this is not the case for GABA-immunoreactive neurons in the rat visual cortex. He finds that GABA-immunoreactive neurons follow the same inside-out gradient as do nonimmunoreactive neurons. Neurogenesis in the mouse and rat occurs during a very short period of time, and there is considerable overlap in the genesis of the various layers. The ferret has a longer and more spatially discrete pattern of neurogenesis than that observed in the hamster (Shimada and Langman, 1970; Crossland and Uchwat, 1982), rat (Berry et al., 1964; Hicks and D'Amato, 1968), or mouse (Angevine and Sidman, 1961), affording a more detailed vicw of cortical ncurogenesis. The discrete and prolonged pattern of neurogenesis in the ferret visual cortex is similar to that observed in primates (Rakic, 1974) and cats (Luskin and Shatz, 1985a).

A related issue is whether or not interneurons of different sizes follow the same pattern of neurogenesis. In the cat, separate subpopulations of small and large GABA-immunoreactive neurons that are related to $\mathrm{X}$ and $\mathrm{Y}$ pathways, respectively, are reported in the lateral geniculate nucleus and in layer IV of the visual cortex (Freund et al., 1985; Montero and Zempel, 1985). It is possible that the interneurons related to these different pathways vary in their development, although no difference between the birthdates of class 1 and 2 neurons (Y-cells) and class 2 and 3 neurons (X-cells) in cat geniculate nucleus is found (Hitchcock et al., 1984). Also, if the rate of differentiation of neurons is related to their birthdate, larger interneurons may originate earlier. In a Golgi study of the cat visual cortex, Meyer and Ferres-Torres (1984) find that large basket cells of layers III-V are the first nonpyramidal neurons to develop. In the monkey visual cortex, Lund et al. (1977), using the Golgi technique, find that the rate of neuronal maturation is related to size, with larger neurons differentiating before smaller neurons.

In the present study, the laminar positions of GABA-immunoreactive and nonimmunoreactive neurons generated on different days of development are compared in the adult ferret. Also examined is the size of the GABA-immunoreactive neurons produced at different times in development.

Preliminary reports of this work were presented previously (Peduzzi and Hickey, 1985; Peduzzi, 1986).

\section{Materials and Methods}

Time-bred pregnant ferrets were obtained from Marshall Farms, NY. For the embryonic injection of ${ }^{3} \mathrm{H}$-thymidine, pregnant ferrets were anesthetized by intramuscular injections of ketamine $(40 \mathrm{mg} / \mathrm{kg})$ and acepromazine $(4 \mathrm{mg} / \mathrm{kg})$, then a laparotomy was performed, as previously described by Hickey et al. (1983). Each embryo received 0.25 $\mathrm{mCi}$ of ${ }^{3} \mathrm{H}$-thymidine (ICN Radiochemicals, no. 24060; thymidine[methyl- $\left.{ }^{3} \mathrm{H}\right], 60-90 \mathrm{Ci} / \mathrm{mmol}$ in sterile aqueous solution) injected into the allantoic cavity. The pregnant ferrets were then allowed to deliver normally (gestation $=41 \mathrm{~d}$ ). For postnatal injections, $0.5 \mathrm{mCi}$

\begin{tabular}{lll}
\hline Table 1. Day of ${ }^{\mathbf{3}} \mathbf{H}-$ thymidine injection and age when killed (days) \\
Animal no. & Age at injection & $\begin{array}{l}\text { Age when } \\
\text { killed }\end{array}$ \\
\hline 436 & E22 & 176 \\
408 & E26 & 166 \\
412 & E30 & 304 \\
425 & E34 & 278 \\
362 & E38 & 53 \\
421 & P2 & 227 \\
422 & P6 & 181 \\
437 & P10 & 191 \\
\hline
\end{tabular}

of ${ }^{3} \mathrm{H}$-thymidine was injected intraperitoneally. All animals were allowed to survive to adulthood. The age of ${ }^{3} \mathrm{H}$-thymidine injection and the age at which each animal was killed are given in Table 1 .

While deeply anesthetized, animals were perfused through the heart with PBS, $\mathrm{pH} 7.2$, followed by Zamboni's fixative [ $2 \%$ paraformaldehyde, $15 \%$ saturated picric acid in $0.1 \mathrm{M}$ phosphate buffer $(\mathrm{PB}), \mathrm{pH} 7.2$, then followed by the same fixative with $10 \%$ sucrose. The brain was postfixed for $2-5 \mathrm{hr}$ and then placed in $20 \%$ sucrose in PB overnight to facilitate sectioning. Alternate horizontal frozen sections close to the representation of area centralis were taken for immunohistochemistry (15 $\mu \mathrm{m})$, Nissl staining $(15 \mu \mathrm{m})$, and AChE histochemistry $(60 \mu \mathrm{m})$. A modification of the procedure from Dean et al. (1982) was used for AChE histochemistry. The Nissl and AChE sections facilitated identification of the boundaries of the primary visual cortex.

Sections for immunohistochemistry were collected in PBS, pH 7.4, placed in $0.3 \%$ Triton X-100 in PBS for $10 \mathrm{~min}$, rinsed (all rinses were 10 times with PBS), then blocked in 10\% normal goat serum in PBS for $1 / 2 \mathrm{hr}$. Sections were placed in GABA antiserum (Immunonuclear; diluted 1:3000 in PBS with $1 \%$ goat serum) for $48 \mathrm{hr}$ at $4^{\circ} \mathrm{C}$. [See Maley and Newton (1985) for a description of the production and specificity of this antiserum.] Sections were occasionally placed on a shaker during this incubation. In each group, sections were also processed using a variety of other antisera. After rinsing, sections were placed in goat antirabbit antiserum (Sigma; diluted 1:300 in PBS with 1\% goat serum) for $90 \mathrm{~min}$ at room temperature. Sections were rinsed, then incubated in rabbit peroxidase anti-peroxidase (PAP) (Sigma; diluted 1:500 in PBS with $1 \%$ goat serum) for $90 \mathrm{~min}$ at room temperature. After rinsing again, sections were reacted using $0.05 \%$ 3,3'-diaminobenzidine tetrahydrochloride (Sigma) with $0.01 \%$ hydrogen peroxide in PBS for 10 min. After several rinses, sections were mounted on slides. Control sections that lacked either primary antiserum, secondary antiserum, or PAP were also processed. All control sections lacked immunoreactivity. For autoradiography, slides were defatted, then hydrated and dipped in N'IB-2 emulsion. After 4 weeks, slides were developed and coverslipped. Following analysis of the GABA-immunoreactive neurons, the coverslips were removed and sections were Nissl-stained.

\section{Data analysis}

The cross-sectional area of the neuronal soma and the position of neurons within the visual cortex were determined using a microscope with an $X-Y$ microscope stage encoder coupled to an Apple IIe computer using the Bioquant system software (Nashville, TN). It was possible to code individual neurons as to whether they were immunoreactive and whether they had silver grains over their nucleus. The criteria used for neuronal identification were a vesiculated nucleus and prominent nucleolus. In GABA-immunoreactive neurons, the nucleolus was often present as a negative image. After sections were counterstained, the laminar locations (upper or lower parts of layers I, II-III, IV, V, VI, and white matter) of the plotted positions of the individual neurons were determined. Layers II and III were considered logether because of the difficulty in determining the laminar boundary between them.

GABA-immunoreactive neurons. Camera lucida drawings of GABAimmunoreactive neurons were made using a $100 \times$ oil-immersion objective. The percentages of neurons that were GABA-immunoreactive in a strip of visual cortex $(190 \mu \mathrm{m}$ wide) from pia to white matter at 8 different mediolateral positions were determined in 3 different animals. This was to establish whether there was any difference in the percentage 


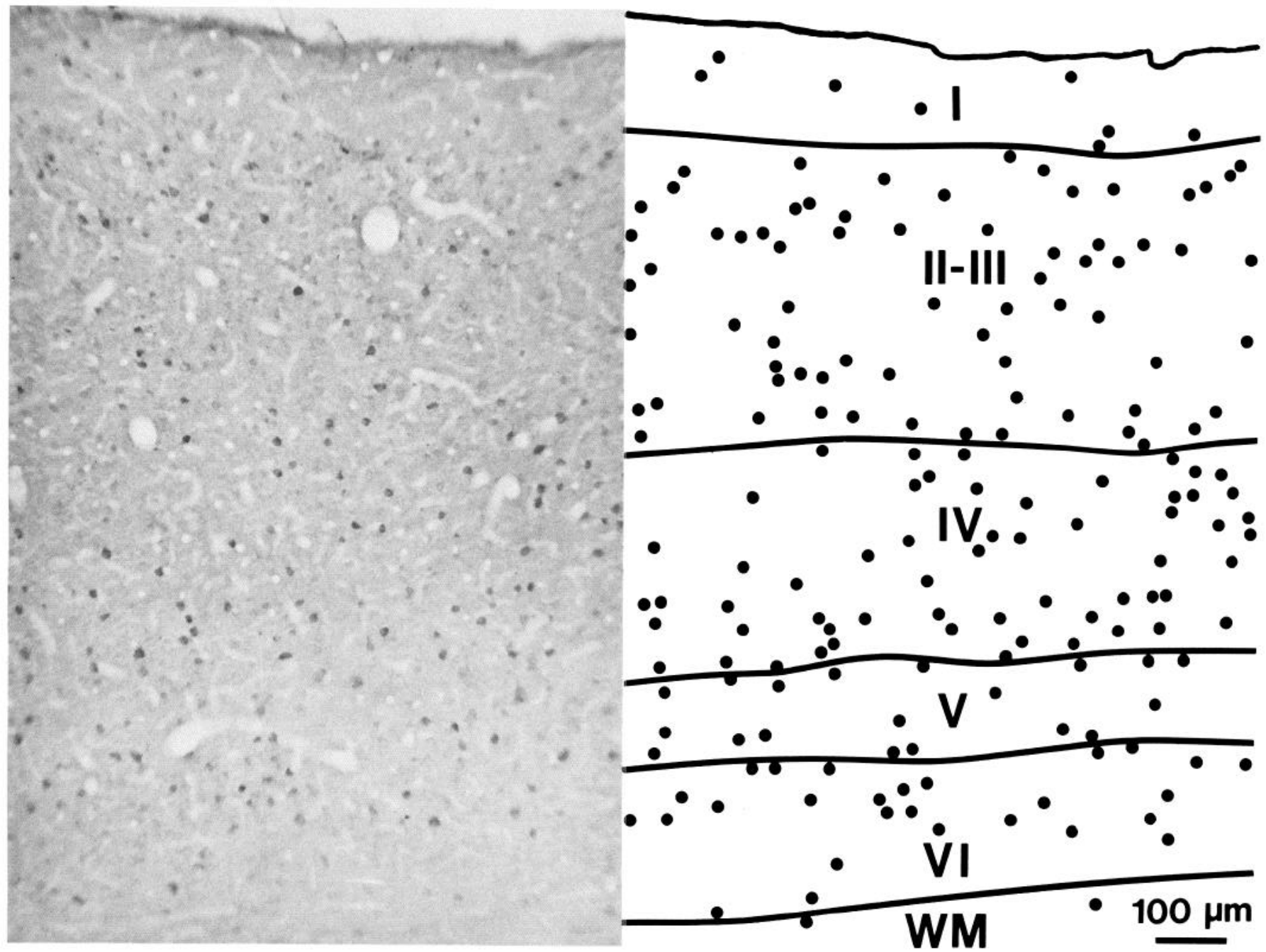

Figure 1. Left, Photomicrograph showing the distribution of GABA-immunoreactive neurons in a horizontal section through the ferret visual cortex. Right, the corresponding plot showing the position of GABA-immunoreactive neurons and laminar boundaries.

of GABA-immunoreactive neurons at the different mediolateral positions of the primary visual cortex. Additionally, the percentages of neurons that were GABA-immunoreactive in the entire visual cortex and also in each layer of the visual cortex were determined using at least 3 strips of visual cortex from 5 different animals. The soma crosssectional areas of GABA-immunoreactive neurons were determined for at least 161 neurons (161-934) in each of the 8 ferrets.

Double-labeled neurons. The positions and sizes of double-labeled neurons were determined. A double-labeled neuron is a GABA-immunoreactive neuron that is heavily labeled with silver grains (between the half-maximal and maximal number of silver grains for that animal). Using these criteria for the number of silver grains is sufficient to identify a neuron actually generated on the day of ${ }^{3} \mathrm{H}$-thymidine injection (Hickey et al., 1983). For each animal analyzed, the positions and soma crosssectional areas of at least $75(75-136)$ double-labeled neurons were determined. In the animal injected with ${ }^{3} \mathrm{H}$-thymidine on $\mathrm{P} 10$, it was necessary to analyze a large number of sections in order to obtain a sufficient number of double-labeled neurons.

Birthdate of nonimmunoreactive neurons. The positions of neurons that lacked GABA immunoreactivity but that had a large number of silver grains over the nucleus were plotted. For each animal, the positions and laminar locations of at least 152 (152-602) nonimmunoreactive neurons were determined. In each section, the entire extent of area 17 was analyzed. It is doubtful that any of the nonimmunoreactive neurons with silver grains over the nucleus lacked GABA immunoreactivity because of poor penetration of the antiserum, since beta particles of the tritium can only travel a few microns to expose the emulsion thus only neurons in the upper $3 \mu \mathrm{m}$ of the section can be labeled with silver grains (Rogers, 1979). However, other factors may influence whether a neuron is GABA-immunoreactive (see Discussion).

\section{Results}

GABA neuron morphology. The pattern of GABA-immunoreactive neurons in the visual cortex was very consistent between animals, using the immunohistochemical methods described. GABA-immunoreactive neurons are present in every cortical layer and appear to be fairly evenly distributed across the layers of the cortex (Fig. 1). However, since neuronal density varies in the different layers of the cortex, the percentage of GABA-immunoreactive neurons in the different layers is not equal (see below). Examples of camera lucida drawings of GABAimmunoreactive neurons from each of the cortical layers taken from several animals are illustrated in Figure 2. GABA-immunoreactive neurons are a heterogeneous population of neurons that can be broadly classified as having bipolar, bitufted, or multipolar morphology. In the large number of sections examined, GABA-immunoreactive neurons, with their proximal dendrites oriented horizontally, are often seen in layer I and lower layer VI. Attempts made to find consistent patterns in dendritic morphology within the other layers were unsuccessful. On the basis of the limited dendritic morphology that was re- 

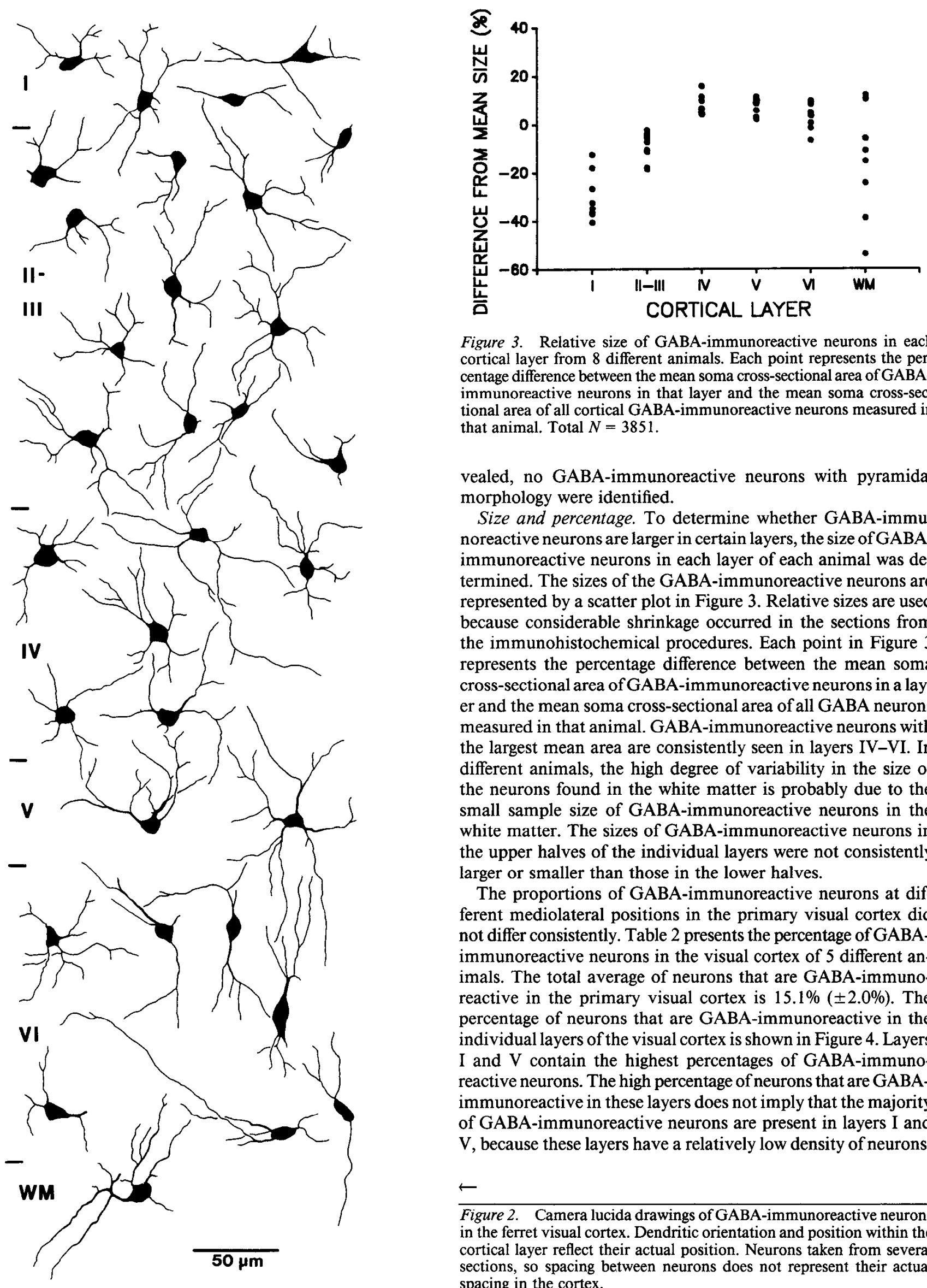

Figure 3. Relative size of GABA-immunoreactive neurons in each cortical layer from 8 different animals. Each point represents the percentage difference between the mean soma cross-sectional area of GABAimmunoreactive neurons in that layer and the mean soma cross-sectional area of all cortical GABA-immunoreactive neurons measured in that animal. Total $N=3851$.

vealed, no GABA-immunoreactive neurons with pyramidal morphology were identified.

Size and percentage. To determine whether GABA-immunoreactive neurons are larger in certain layers, the size of GABAimmunoreactive neurons in each layer of each animal was determined. The sizes of the GABA-immunoreactive neurons are represented by a scatter plot in Figure 3. Relative sizes are used because considerable shrinkage occurred in the sections from the immunohistochemical procedures. Each point in Figure 3 represents the percentage difference between the mean soma cross-sectional area of GABA-immunoreactive neurons in a layer and the mean soma cross-sectional area of all GABA neurons measured in that animal. GABA-immunoreactive neurons with the largest mean area are consistently seen in layers IV-VI. In different animals, the high degree of variability in the size of the neurons found in the white matter is probably due to the small sample size of GABA-immunoreactive neurons in the white matter. The sizes of GABA-immunoreactive neurons in the upper halves of the individual layers were not consistently larger or smaller than those in the lower halves.

The proportions of GABA-immunoreactive neurons at different mediolateral positions in the primary visual cortex did not differ consistently. Table 2 presents the percentage of GABAimmunoreactive neurons in the visual cortex of 5 different animals. The total average of neurons that are GABA-immunoreactive in the primary visual cortex is $15.1 \%( \pm 2.0 \%)$. The percentage of neurons that are GABA-immunoreactive in the individual layers of the visual cortex is shown in Figure 4. Layers I and V contain the highest percentages of GABA-immunoreactive neurons. The high percentage of neurons that are GABAimmunoreactive in these layers does not imply that the majority of GABA-immunoreactive neurons are present in layers I and $\mathrm{V}$, because these layers have a relatively low density of neurons.

Figure 2. Camera lucida drawings of GABA-immunoreactive neurons in the ferret visual cortex. Dendritic orientation and position within the cortical layer reflect their actual position. Neurons taken from several sections, so spacing between neurons does not represent their actual spacing in the cortex. 


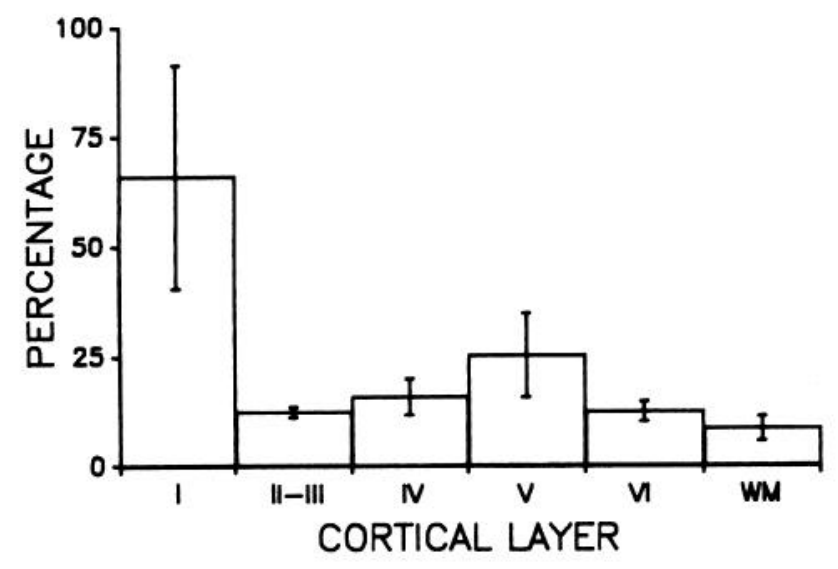

Figure 4. Percentage of neurons $( \pm \mathrm{SE})$ that are GABA-immunoreactive in each layer of the visual cortex. Data obtained from 5 different animals. Total average of GABA-immunoreactive neurons in the visual cortex was $15.1 \%( \pm 2.0 \% \mathrm{SD})$.

\section{Birthdate of subpopulations}

Examples of cells from a section processed for immunohistochemistry and autoradiography are shown in Figure 5. The cell on the far right is a neuron that is not GABA-immunoreactive. It would, however, be considered as having undergone its final cell division on the day that this animal received an injection of ${ }^{3} \mathrm{H}$-thymidine, since the number of silver grains over the nucleus is between the maximal and half-maximal number of silver grains observed in this animal. The second cell from the left is an example of a GABA-immunoreactive neuron which would also be considered to have been generated on this developmental day. The other 2 GABA-immunoreactive neurons have insufficient silver grains over the nucleus to be considered as having the same birthdate.

Position of double-labeled neurons. The laminar distribution in the adult of neurons generated on various developmental days is depicted in Figure 6. The total number of GABA-immunoreactive neurons generated on each day (75-136 neurons plotted for each animal) was taken as $100 \%$, and is represented by an upright solid histogram. The number of neurons that lacked GABA immunoreactivity that were generated on each day (152-602 neurons plotted for each animal) was also taken as $100 \%$, and its percentage distribution in each layer is shown by the inverted histogram with the diagonal cross-hatching. The reason for analyzing unequal numbers of GABA-immunoreactive and nonimmunoreactive neurons was that similar regions of the visual cortex could be sampled in each case. The horizontal bars above the histograms represent the radial distribution of those neurons falling between the 25 th and 75 th per-

Table 2. Percentage of GABA-immunoreactive neurons $(\mathrm{GABA}+)$ in layers I-VI of the ferret visual cortex

\begin{tabular}{lrrrl}
$\begin{array}{l}\text { Animal } \\
\text { no. }\end{array}$ & $\begin{array}{l}\text { GABA } \\
\text { cells }\end{array}$ & $\begin{array}{l}\text { Non-GABA } \\
\text { cells }\end{array}$ & Total cells & Percent \\
\hline 436 & 209 & 1075 & 1284 & 16.28 \\
412 & 68 & 336 & 404 & 16.83 \\
425 & 235 & 1291 & 1526 & 15.40 \\
421 & 141 & 1111 & 1252 & 11.26 \\
437 & 56 & 299 & 355 & 15.77 \\
\hline
\end{tabular}

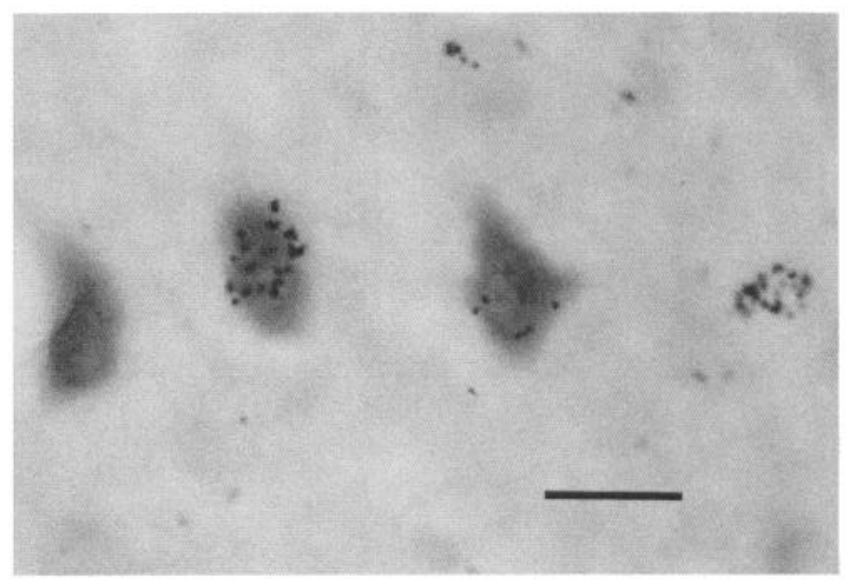

Figure 5. Photomicrograph of neurons in the ferret visual cortex. The cell on the far right with a large number of silver grains over its nucleus is not GABA-immunoreactive and would be considered to be generated on the day that this animal was injected with ${ }^{3} \mathrm{H}$-thymidine. The second cell from the left is a GABA-immunoreactive neuron with a large number of silver grains (double-labeled), therefore also generated on the day that this animal was injected with ${ }^{3} \mathrm{H}$-thymidine. The other 2 cells are GABA-immunoreactive neurons with few or no silver grains over their nucleus and would not be considered as having been generated on the day this animal received ${ }^{3} \mathrm{H}$-thymidine. Scale bar, $15 \mu \mathrm{m}$.

centiles of the population of cells generated on a given developmental day. Therefore, $50 \%$ of the radioactively labeled neurons lie within the cortical positions spanned by the bar. The upper, solid horizontal bar denotes the GABA-immunoreactive neurons, and the bar with cross-hatching represents the nonimmunoreactive neurons. The median position of all the GABA-immunoreactive neurons or nonimmunoreactive neurons generated on each day is represented by the arrowhead on each horizontal bar. For example, in Figure $6 \mathrm{~A}$ (neurons generated on E22), $50 \%$ of the GABA-immunoreactive neurons reside in the region between lower layer $\mathrm{V}$ and lower layer $\mathrm{VI}$ (width of the bar), and the median laminar position is approximately the middle of upper VI (arrowhead). Also, $50 \%$ of the nonimmunoreactive neurons generated on this day are found between the middle of lower layer VI and upper white matter, and the median position is in the white matter.

In looking at the histograms (Fig. 6) across the days of neurogenesis, it is found that GABA-immunoreactive neurons follow an inside-out pattern of cell production similar to that seen for neurons that are not GABA-immunoreactive. Although there are slight differences in the laminar distribution between the GABA-immunoreactive and nonimmunoreactive neurons generated on the same day, the distribution of the 2 subpopulations generated on most developmental days is fairly similar. However, one difference observed is that the early-generated (E22E30) neurons in layer I and upper layer II-III (which are the exception to the inside-out pattern) consist almost entirely of GABA-immunoreactive neurons.

The inside-out gradient of cell production is even more obvious when we look at the median positions on different developmental days (arrowheads in Fig. 6). The median positions of the GABA-immunoreactive neurons are more superficially located in the cortex, in most cases, than the median positions of the nonimmunoreactive neurons ( 7 out of 8 ). However, the median positions of the 2 subpopulations are very close in at least one-half of the animals. Using the median test (Siegel, 
1956), the positions of the GABA-immunoreactive neurons in the adult are not significantly different in central tendencies from the nonimmunoreactive neurons generated, except for those produced on E22, E26, and P2. Eliminating the neurons in layers I and II-III from consideration in the animals injected on E22 and E26 did not change the results of this test.

However, the 2 groups (GABA-immunoreactive and nonimmunoreactive) generated on a given day are not drawn from the same population [Mann-Whitney $U$ test (Siegel, 1956); $p<$ 0.011 , based on the radial distribution of their cortical positions. For each of the days examined, the distance between the 25 th and 75th percentiles (width of the horizontal bar in Fig. 6) is greater in the subpopulation of GABA-immunoreactive neurons than in the nonimmunoreactive neurons. Furthermore, the final positions of the GABA-immunoreactive neurons generated on a given day are significantly more variable $[F$ test for the differences of variances (Sokal and Rohlf, 1981), 2-tailed; $p<$ 0.02 ] than for neurons lacking immunoreactivity produced on the same day. Eliminating the neurons in layers I and II-III from consideration in the animals injected on E22-E30 did not change the results of this test. The distance between the 25 th and 75 th percentiles in nonimmunoreactive neurons is generally restricted to 1 or 2 layers, except in the E30-injected animal. The wide distribution of neurons on E30 is probably due to the large number of neurons generated on this day.

Size of double-labeled neurons. The mean cross-sectional areas of GABA-immunoreactive neurons generated at successively later times in neurogenesis are progressively smaller, except for one animal ( ${ }^{3} \mathrm{H}$-thymidine injection on E38), which had exceptionally large neurons. The relative size of the GABA-immunoreactive neurons generated on each of the devclopmental days is shown in Figure 7. The relative size is the mean cross-sectional area of the double-labeled neurons divided by the mean crosssectional area of all the GABA-immunoreactive neurons measured in that animal. The size of GABA-immunoreactive neurons generated later declines considerably compared to those generated early in neurogenesis. In Figure 8 are histograms showing the distribution of the cross-sectional areas of GABAimmunoreactive neurons generated on 4 developmental days. Considerable overlap is seen in the cell-size distribution of the GABA-immunoreactive neurons generated on different days, suggesting that GABA-immunoreactive neurons of all sizes are generated throughout neurogenesis. However, a greater number of smaller GABA-immunoreactive neurons and fewer larger neurons are generated late in neurogenesis.

A possible reason for the decline in the mean area of lategenerated GABA-immunoreactive neurons is that GAB $\Lambda$ neurons are larger in the deeper layers of the cortex and exhibit an inside-out gradient of cell production. To determine whether this is totally responsible for the decline, the relative size of the GABA-immunoreactive neurons generated in each layer was determined. The relative size is the mean cross-sectional area of the GABA-immunoreactive neurons generated on a developmental day in each layer of each animal (double-labeled) divided by the mean cross-sectional area of the GABA-immunoreactive neurons in that layer of the animal. This should eliminate any differences due to the varying sizes of GABA neurons in each layer or to slightly different cell sizes in individual animals. The relative sizes of GABA-immunoreactive neurons in each layer generated on different days in neurogenesis are plotted in Figure 9. Underlining of the developmental days on the $x$-axis indicates the time when the majority of GABA- immunoreactive neurons in that layer were generated. The mean soma sizes of double-labeled neurons generated on some of the developmental days before or after this peak period are calculated from relatively few neurons. A linear regression is used to reveal any trend in the data. All the regression lines for each of the layers have a negative slope, suggesting that the mean sizes of the later-generated GABA-immunoreactive neurons are slightly smaller. In Figure 10 are histograms showing the cellsize distributions of GABA-immunoreactive neurons in layer $V$ that were generated at 4 different times in development. There is again considerable overlap in their distribution, but a greater number of smaller neurons and fewer larger neurons are generated on the later developmental days.

\section{Discussion}

\section{GABA morphology}

The morphology and laminar distribution of GABA-immunoreactive neurons in the ferret visual cortex are similar to those in the population of GAD- or GABA-immunoreactive neurons reported in rat (Ribak, 1978), cat (Fitzpatrick et al., 1983; Gabbott and Somogyi, 1986), and monkey (Hendrickson et al., 1981) visual cortex. The observations in the ferret that a high proportion of layer I neurons are GABA-immunoreactive and that the largest GABA-immunoreactive neurons are present in layers IV-VI agree with findings reported for the cat visual cortex (Gabbott and Somogyi, 1986). The percentage of neurons that are GABA-immunoreactive in the ferret visual cortex (15.1\%) is close to that reported by Fitzpatrick et al. (1983) for GADimmunoreactive neurons in the cat visual cortex (8-15\%). However, it is slightly lower than the $20 \%$ (GABA-immunoreactive neurons) reported by Gabbott and Somogyi (1986) in the cat visual cortex. It appears that the sections (15 $\mu \mathrm{m}$ thick) were completely penetrated by the GABA antiserum since there was no change in the number of GABA-immunoreactive neurons at different focal planes through the section. However, it is possible that the $2 \mu \mathrm{m}$ sections used by Gabbott and Somogyi actually had better penetration of the antiserum. Also, different species may have different percentages of GABA-immunoreactive neurons in a particular area.

A wide variety of factors may affect the actual percentage of GABA-immunoreactive neurons observed. The type of fixative, degree of tissue fixation, and even the amount of detergent used may influence the immunoreactivity of the neurons. Additional factors that may be important include the immunohistochemical reagents and incubation parameters used. Furthermore, the metabolic state of the neurons affects the percentage of GABAimmunoreactive neurons (Hendry and Jones, 1986). Although every effort was made to optimize conditions, every neuron that actually uses GABA as a neurotransmitter may not have been revealed.

\section{Birthdate of subpopulations}

The pattern of neurogenesis of the GABA-immunoreactive neurons is, on the whole, quite similar to that observed for neurons that are not GABA-immunoreactive. Both exhibit a prominent inside-out pattern of neurogenesis. However, one difference observed between the 2 patterns of neurogenesis relates to neurons generated on E22. The median position of the neurons that lacked GABA immunoreactivity generated on that day is in the white matter. This is not the case for the GABA-immunoreactive neurons, whose median position is in layer VI. The difference is probably due to the fairly low percentage of neurons that 


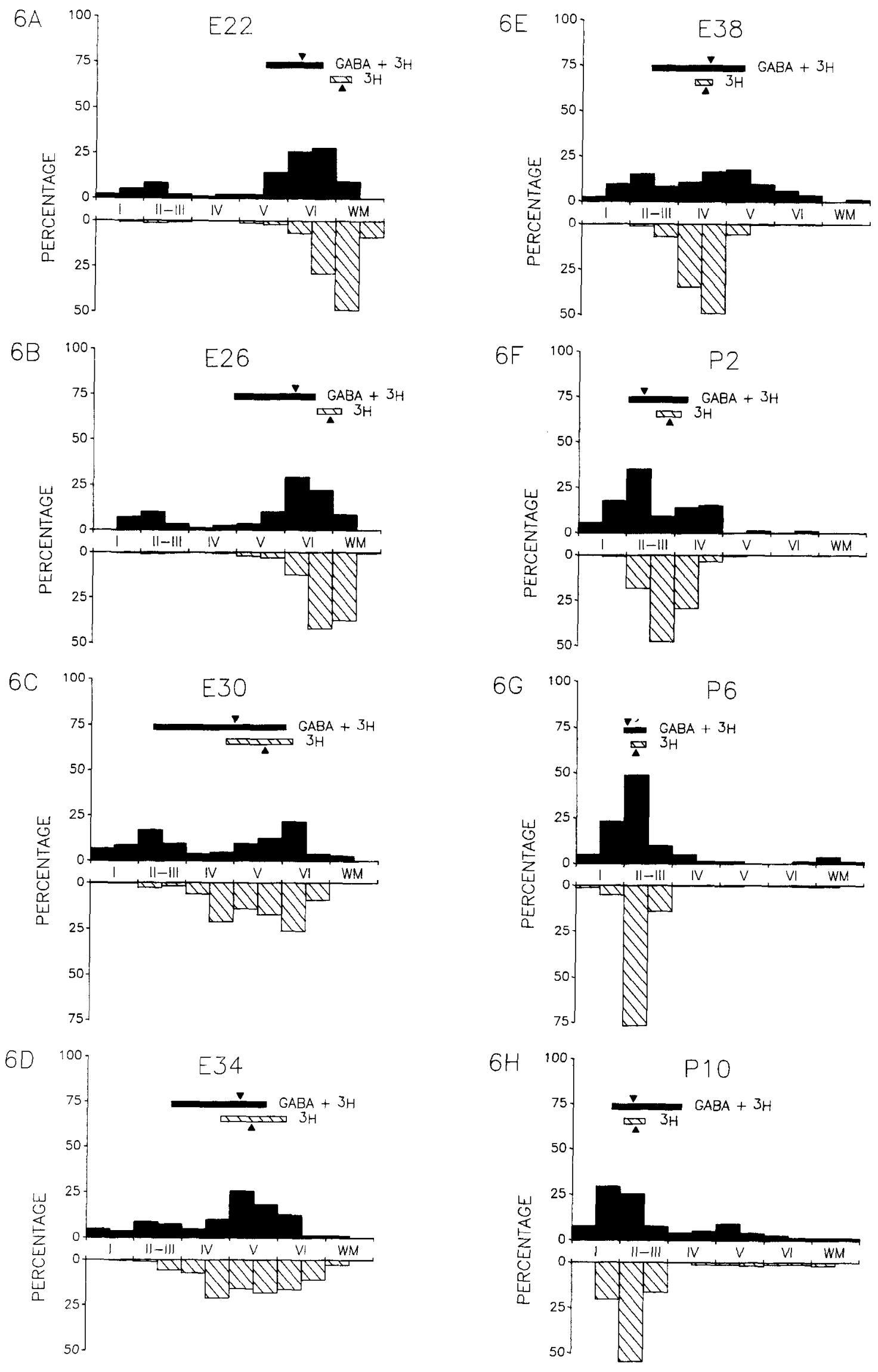




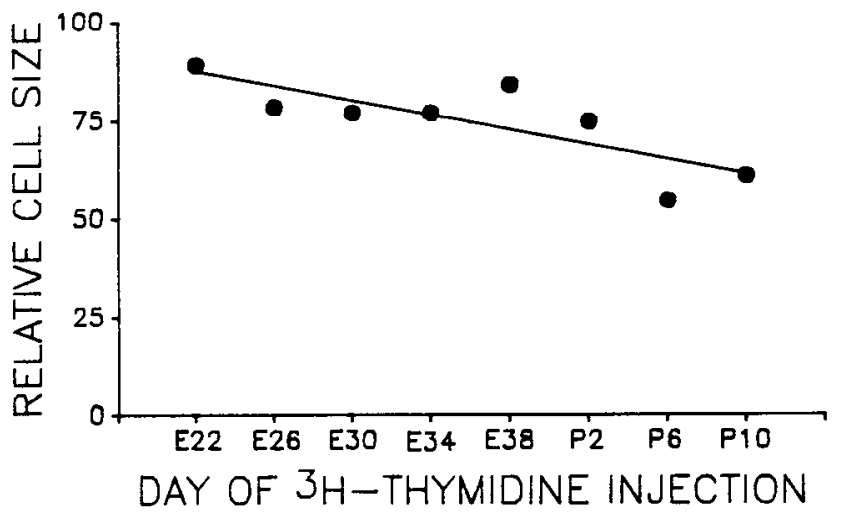

Figure 7. Relative cell size of all the GABA-immunoreactive neurons produced on the various days of development. Relative cell size is the mean soma cross-sectional area of the GABA-immunoreactive neurons generated/the mean soma cross-sectional area of all GABA-immunoreactive neurons measured in that animal in area $17 \times 100 \%$. Linear regression is used to show trends in the data. The dramatic decrease is due in part to the fact that GABA-immunoreactive neurons are larger in the deeper layers of the visual cortex (Fig. 4), and there is an insideout gradient in the production of GABA-immunoreactive neurons (Fig. $6)$.

are GABA-immunoreactive in the white matter of the adult ferret. In the developing ferret, a large proportion of neurons in the white matter are GABA-immunoreactive. Therefore, it is possible that this difference between the median positions of the GABA-immunoreactive and nonimmunoreactive neurons generated on E22 would not be present in the developing ferret. It is not known, however, whether these GABA-immunorcactive neurons in the white matter of the immature ferret die or lose their GABA immunoreactivity. The large number of neurons generated on E22 that are found in the white matter of the adult ferret differs from the results of Luskin and Shatz (1985b), who found very few neurons in the white matter of the adult cat. This may be due to species differences.

Another difference between the patterns of neurogenesis of GABA-immunoreactive neurons and nonimmunoreactive neurons is that the early-generated neurons (E22-E30) in layer I and upper layer II-III consist almost entirely of GABA-immunoreactive neurons. The layer II-III GABA-immunoreactive neurons generated toward the beginning of neurogenesis are produced much earlier than the majority of neurons in this layer. Some of these neurons are at the I-II border, and are difficult to categorize as being in layer I or II. However, others are clearly residing in layer II-III and not at the I-II border. Perhaps these neurons are part of the primordial plexiform layer described by Marin-Padilla (1971) or possibly they are ectopic layer I cells. An analysis of the peptides contained in these neurons may reveal whether they are similar to the other early-generated layer I cells. At least a few GABA-immunoreactive layer I neurons
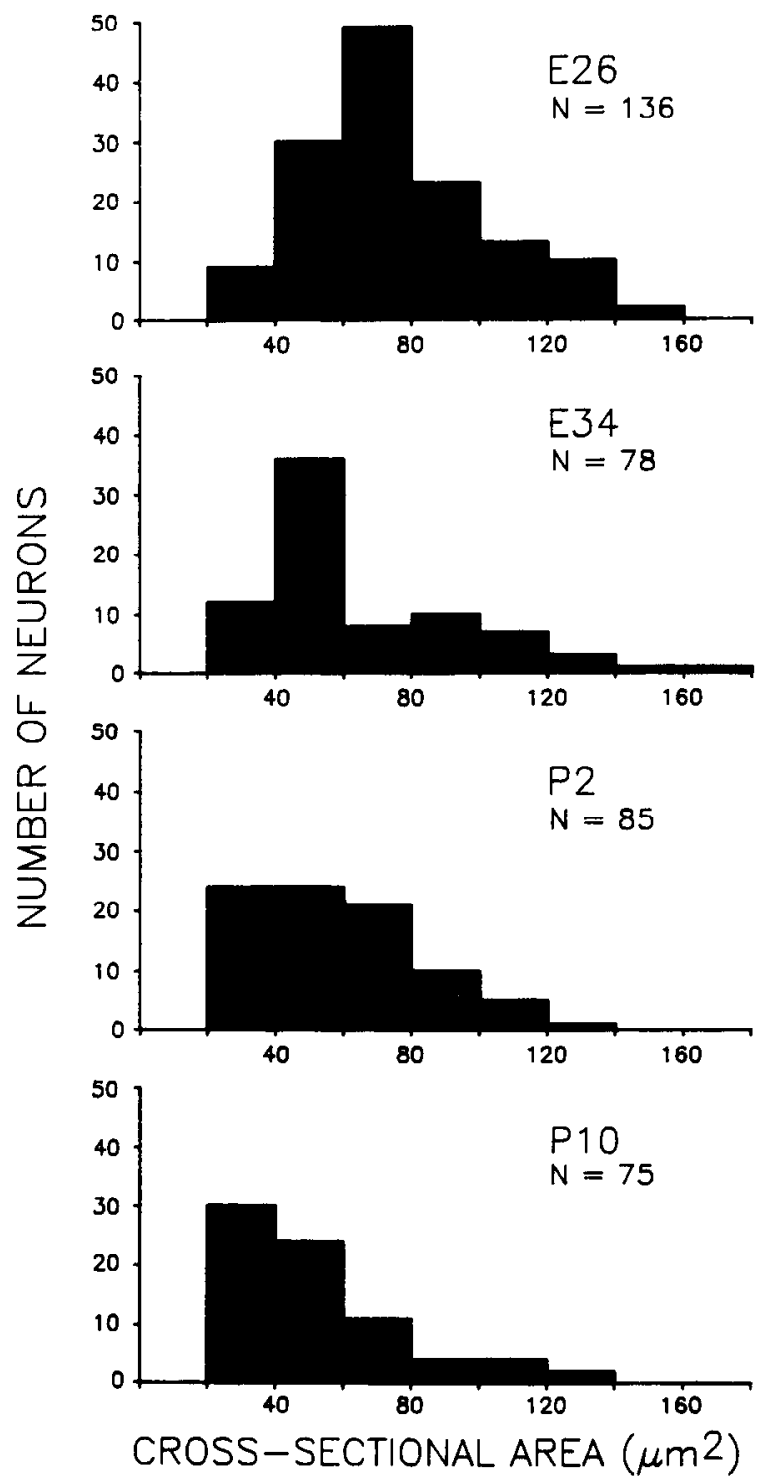

Figure 8. Histograms showing the cell-size distribution of the GABAimmunoreactive neurons generated on 4 different days in development, taken at $8 \mathrm{~d}$ intervals. Although the cell-size distribution of the 4 different animals overlaps, there seem to be more smaller cells generated later in neurogenesis.

are generated on every developmental day examined. However, there are actually 2 main periods when layer I neurons are generated-early and late in neurogenesis (Jackson, 1986). Early-generated layer I neurons consist almost entirely of GABAimmunoreactive neurons, while late-generated layer I neurons also include nonimmunoreactive neurons. Other slight differences in median position between the 2 subpopulations of neu-

Figure 6. Histograms of the percentage (in each cortical sublayer) of the total number of neurons that were produced on a given day in development. The laminar distribution in the adult ferret of all the GABA-immunoreactive neurons generated on each day in development is represented by the upright solid histograms. The inverted histograms with diagonal cross-hatching represent the laminar distribution of neurons that were not GABAimmunoreactive, produced on the same day. Percentile information is given in the bars above each histogram. The total range in the radial positions (deepest to most superficial) of neurons generated on each day of development is from the 0 to 100 th percentile. The horizontal bars shown above each histogram represent the radial distribution of those neurons falling between the 25 th and 75 th percentiles of the population of cells generated on a given developmental day. The upper solid horizontal bars denote the GABA-immunoreactive neurons, and the bars with cross-hatching represent the nonimmunoreactive neurons. The arrowhead on each bar denotes the median position (50th percentile). 


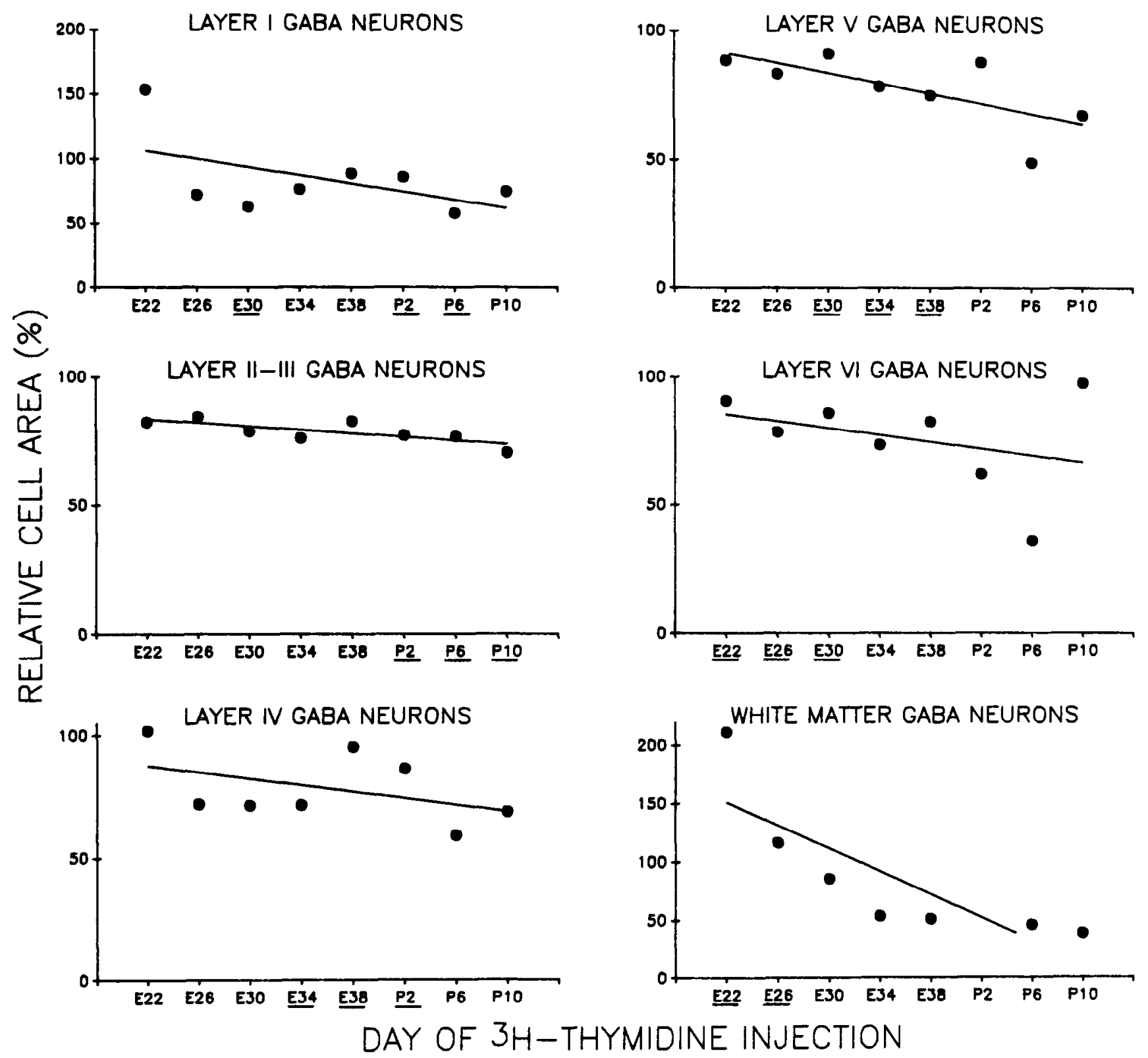

Figure 9. Relative size of GABA-immunoreactive neurons generated on different days for each layer. Relative cell area is the mean soma crosssectional area of GABA-immunoreactive neurons generated in that layer/the mean soma cross-sectional area of all GABA-immunoreactive neurons measured in that layer in that animal $\times 100 \%$. Underlining of certain days on the $x$-axis denotes the time when the majority of the GABAimmunoreactive neurons in that layer were produced. Data obtained before and after these days are based on relatively few neurons. Linear regression is used to reveal trends in data. All regression lines have negative slopes. Note that the $y$-axis is different for layer I and white matter neurons, which minimizes the slope relative to the other days.

rons may be due to differences in the percentages of GABAimmunoreactive neurons in the various layers.

The finding that GABA-immunoreactive neurons in the ferret visual cortex generally follow the same inside-out pattern as nonimmunoreactive neurons is similar to results in the rat visual cortex (Miller, 1985) and mouse somatosensory cortex (Fairén et al., 1986). The results presented here do not support the findings of Wolff et al. (1978) that GABA-accumulating neurons destined for all of the cortical layers are generated during most of neurogenesis in the rat visual cortex. Perhaps it is not possible to obtain a sufficient number of neurons to document the insideout gradient within the increased scatter of GABA neurons using the ${ }^{3} \mathrm{H}-\mathrm{GABA}$ injection technique. Results presented here also differ from the finding that the peak of neurogenesis of GADimmunoreactive neurons precedes the peak of nonimmunoreactive neurons in the mouse hippocampus (Soriano et al., 1986). However, it is not clear whether the neurogenesis of these 2 subpopulations varies within individual layers of the hippocampus. If the spatiotemporal gradient is such that cells in layers that contain predominantly nonimmunoreactive neurons (pyramidal and granule cells) are produced later in development, this may be responsible for the overall difference between the peaks of neurogenesis in these 2 subpopulations.

If GABA-immunoreactive neurons are interneurons in the 
cortex, the present results suggest that the interneurons in the primary visual cortex are produced at the same time as are projecting neurons. In a Golgi study of the rat visual cortex, Parnavelas et al. (1978) also found that pyramidal and nonpyramidal neurons in the same layer develop at the same time. This may be a general cortical phenomenon, given the similar results in somatosensory cortex (Fairén et al., 1986). Whether interneurons are produced at the same time as projecting neurons in other regions of the brain is not known. In the past, this issue has been confused by studies that lacked quantification, or studies in an area where there is a strong spatiotemporal gradient and where interneurons are localized in a particular layer or subdivision of this area.

The distribution, across the radial axis of the cortex, of neurons generated on a single day of development (reflected in the difference between the positions of the 25 th and 75 th percentiles in each animal in Figure 6) is consistently wider for the GABAimmunoreactive neurons than for the nonimmunoreactive neurons. This wider distribution is also mentioned in the study of the development of GAD-immunoreactive neurons in the mouse somatosensory cortex (Fairén et al., 1986). All the GABA-immunoreactive neurons generated on a given developmental day do not lie more superficially or deeper than the nonimmunoreactive neurons generated on the same day. It may be that examining subpopulations of GABA-immunoreactive neurons would reveal some consistent trend in these subpopulations. In the visual cortex, different subpopulations of GABA-immunoreactive neurons are also immunoreactive for somatostatin, cholecystokinin (CCK), or neuropeptide Y (Hendry et al., 1984; Somogyi et al., 1984).

The reason for the broader distribution in the radial position of the GABA-immunoreactive neurons generated on a single day of development is not known. One possible explanation, given by Wolff et al. (1978), is that interneurons and projection neurons migrate to their final positions via different mechanisms. However, the differences in their patterns of neurogenesis may not be great enough to say that another mechanism must exist for their migration. There may be some difference (possibly positional cues) in the mechanism that determines the final position of GABA-immunoreactive neurons produced on a given day of neurogenesis that leads to their more variable laminar distribution. Perhaps the most important determinant of the position of a GABA neuron is the proximity of another GABA neuron, since GABA-immunoreactive neurons appear fairly evenly distributed across the cortex. This idea is weakened by the fact that occasionally 2 or more GABA-immunoreactive ncurons are seen in fairly close proximity. It is possible, however, that the GABA-immunoreactive neurons that are close together are actually different types of GABA neurons. For example, it may be functionally more important in determining their final position that large basket cells (a type of GABA neuron) are spaced evenly from each other than that they recognize laminar boundaries. Regular spacing of specific types of neurons (ON- and OFF- $\alpha$ ganglion cells) is observed in the cat retina (Wässle et al., 1981). Another possible reason for the wider distribution of GABA-immunoreactive neurons is that cell death may affect non-GABA and GABA cells differently.

The role of cell lineage in determining whether neurons use GABA as a transmitter is not known. Given that the time span of neurogenesis of GABA-immunoreactive cells extends for the whole period of cortical neurogenesis, it is possible that the GABA-immunoreactive neurons are derived from distinct pre-

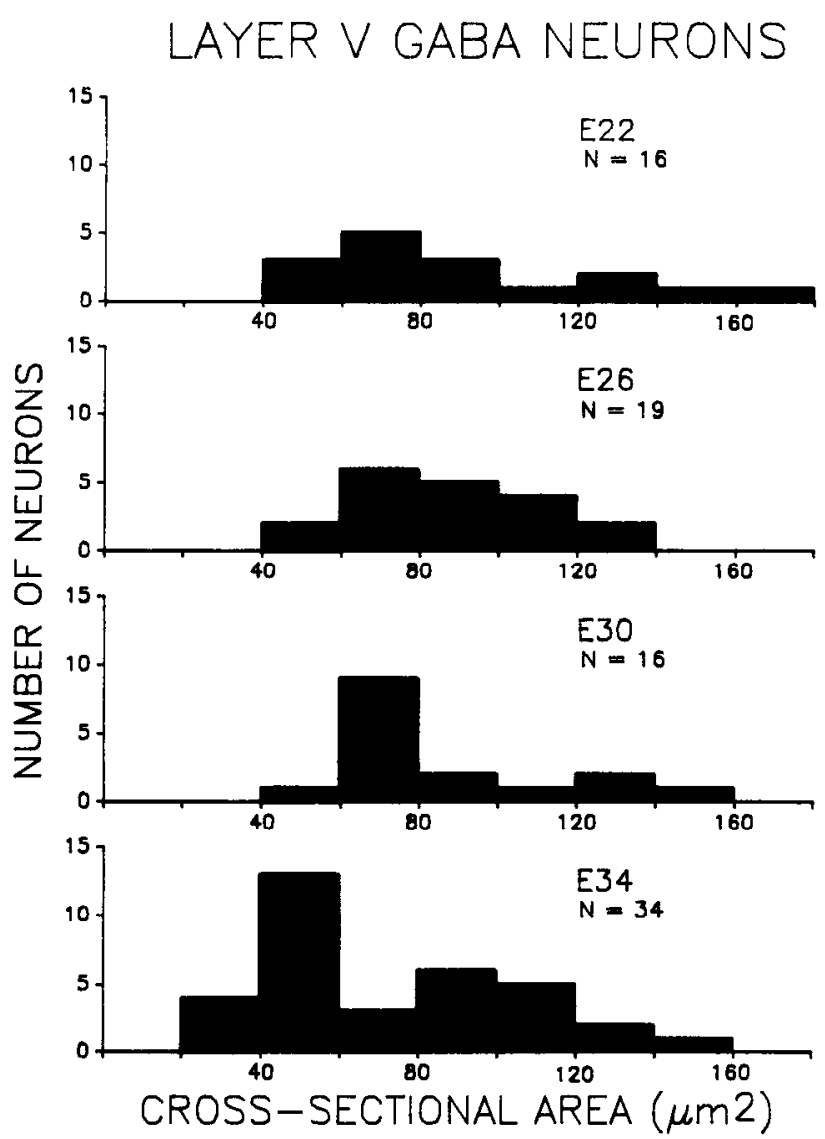

Figure 10. Histograms showing the cell-size distribution of layer $\mathrm{V}$ GABA-immunoreactive neurons generated on 4 different days of development. As in Figure 8, there is considerable overlap in the sizes of neurons in layer $\mathrm{V}$ generated on different days of development, but more smaller neurons are generated late in neurogenesis.

cursor cells in the ventricular zone. Recent studies in the retina (Turner and Cepko, 1987) do not support this idea, however, since a single progenitor is occasionally found to give rise to diverse cell types. Whether similar mechanisms are occurring in the cortex is not known.

The difference in the relative sizes of the GABA-immunoreactive neurons generated early and late is slight, but consistent. One possible explanation is that there are differences in the neurogenesis of the different types of GABA-immunoreactive neurons. Using a combination of techniques, 7 distinct types of GABA-immunoreactive neurons are found in the cat visual cortex: chandelier cells, aspiny and spiny bitufted neurons, neurogliaform cells, deep and large-type basket cells, and clutch cells (Martin et al., 1983; Somogyi and Hodgson, 1985; Somogyi et al., 1985; Somogyi, 1986). For example, if most of the large basket cells are produced before most of the neurogliaform cells (very small neurons), this could lead to the differences in size distribution observed. Supporting this theory is a Golgi study in which the large basket cells were the first nonpyramidal neurons to develop (Meyer and Ferres-Torres, 1984). Another possibility is that interneurons related to the $\mathrm{X}$ and $\mathrm{Y}$ pathways (which vary in size in layer IV of the cat visual cortex according to Freund et al., 1985) vary in their development. However, it was not possible in this study to identify interneurons related to these different pathways. It is also possible that the differences in cell size may reflect some more general phenomenon, such 
as a depletion of metabolic energy in the precursor neurons of late-generated neurons, or some change in metabolism that may be related to the shutdown of the capacity to divide. Although some investigators have found that, during neurogenesis, neurons of all sizes are produced (McAllister and Das, 1977), others have found that neurons of all sizes are generated during most of neurogenesis, but that primarily small neurons are generated at the very end of neurogenesis (Crossland and Uchwat, 1983; Hickey and Hitchcock, 1984). This phenomenon may be more obvious when examining a subpopulation of ncurons, as opposed to the entire population.

Numerous physiological studies of the immature visual cortex reveal the early presence of an inhibitory system (Hubel and Wiesel, 1963; Blakemore and Van Sluyters, 1975). Since the GABA-immunoreactive neurons are produced from the start of neurogenesis in the ferret visual cortex, these results are not surprising. In a more recent physiological study, Tsumoto and Sato (1985) suggest that inhibitory neurons in layer V may mature before inhibitory neurons in deeper or more superficial layers. None of the results presented here suggests that layer $\mathrm{V}$ neurons develop before layer VI, although there is overlap in their neurogenesis. However, it is possible that the maturation of a neuron is not related to its birthdate. Studies under way, in which various subpopulations of neurons are examined, may provide additional information about neuronal development.

\section{References}

Angevine, J. B. (1970) Time of neuron origin in the diencephalon of the mouse. An autoradiographic study. J. Comp. Neurol. 139: 129188.

Angevine, J. B., and R. L. Sidman (1961) Autoradiographic study of cell migration during histogenesis of cerebral cortex in the mouse. Nature 192: 766-768.

Berry, M., A. W. Rogers, and J. T. Eayrs (1964) Pattern of cell migration during cortical histogenesis. Nature 203: 591-593.

Blakemore, C., and R. C. Van Sluyters (1975) Innate and environmental factors in the development of the kitten's visual cortex. J. Physiol. (Lond.) 248: 663-716.

Chronwall, B., and J. R. Wolff (1980) Prenatal and postnatal development of GABA-accumulating cells in the occipital neocortex of rat. J. Comp. Neurol. 190: 187-208.

Clark, R. M., and G. G. S. Collins (1976) The release of endogenous amino acids from the rat visual cortex. J. Physiol. (Lond.) 262: 383400.

Crossland, W. J., and C. J. Uchwat (1982) Neurogenesis in the central visual pathways of the golden hamster. Brain Res. 281: 99-103.

Crossland, W. J., and C. J. Uchwat (1983) Neurogenesis in the chick ventral lateral geniculate and ectomammillary nuclei: Relationship of soma size to birthdate. Dev. Brain Res. 6: 33-46.

Dean, A. F., S. T. Bunch, D. J. Tolhurst, and P. R. Lewis (1982) The distribution of acetylcholinesterase in the lateral geniculate nucleus of the cat and monkey. Brain Res. 244: 123-134.

DeFelipe, J., and E. G. Jones (1985) Vertical organization of $\gamma$-aminobutyric acid-accumulating intrinsic neuronal systems in monkey cerebral cortex. J. Neurosci. 5: 3246-3260.

Emson, P. C., and O. Lindvall (1979) Distribution of putative neurotransmitters in the neocortex. Neuroscience 4: 1-30.

Fairén, A., A. Cobas, and M. Fonseca (1986) Times of generation of glutamic acid decarboxylase immunoreactive neurons in mouse somatosensory cortex. J. Comp. Neurol. 251: 67-83.

Fitzpatrick, D., J. S. Lund, and D. Schmechel (1983) Glutamic acid decarboxylase immunoreactive neurons and terminals in the visual cortex of monkey and cat. Soc. Neurosci. Abstr. 9: 616.

Freund, T. F., K. A. C. Martin, P. Somogyi, and D. Whitteridge (1985) Innervation of cat visual areas 17 and 18 by physiologically identified $\mathrm{X}$ - and Y-type thalamic afferents. II. Identification of postsynaptic targets by GABA immunocytochemistry and Golgi impregnation. J. Comp. Neurol. 242: 275-291.

Gabbott, P. L. A., and P. Somogyi (1986) Quantitative distribution of GABA-immunoreactive neurons in the visual cortex (area 17) of the cat. Exp. Brain Res. 61: 323-331.

Gilbert, C. D., and J. P. Kelly (1975) The projections of cells in different layers of the cat's visual cortex. J. Comp. Neurol. 163: 81106.

Hendrickson, A. E., S. P. Hunt, and J.-Y. Wu (1981) Immunocytochemical localization of glutamic acid decarboxylase in monkey striate cortex. Nature 292: 605-607.

Hendrickson, A., M. Ryan, B. Noble, and J.-Y. Wu (1985) Co-localization of $\left[{ }^{3} \mathrm{H}\right]$ muscimol and antisera to GABA and glutamic acid decarboxylase within the same neurons in monkey retina. Brain Res. 348: 391-396.

Hendry, S. H. C., and E. G. Jones (1986) Reduction in number of immunostained GABAergic neurones in deprived-eye dominance columns of monkey area 17 . Nature 320: 750-753.

Hendry, S. H. C., E. G. Jones, J. DeFelipe, D. Schmechel, C. Brandon, and P. C. Emson (1984) Neuropeptide-containing neurons of the cerebral cortex are also GABAergic. Proc. Natl. Acad. Sci. USA 81 . 6526-6530.

Hendry, S. H. C., H. D. Schwark, E. G. Jones, and J. Yan (1987) Numbers and proportions of GABA-immunoreactive neurons in different areas of monkey cerebral cortex. J. Neurosci. 7: 1503-1519.

Hickey, T. L., and P. F. Hitchcock (1984) Genesis of neurons in the dorsal lateral geniculate of the cat. J. Comp. Neurol. 228: 186-199.

Hickey, T. L., D. R. Whikehart, C. A. Jackson, P. F. Hitchcock, and J. D. Peduzzi (1983) Tritiated thymidine experiments in the cat: A description of techniques and experiments to define the time-course of radioactive thymidine availability. J. Neurosci. Methods $8: 139$ 147.

Hicks, S. P., and C. J. D'Amato (1968) Cell migrations to the isocortex in the rat. Anat. Rec. 160: 619-634.

Hinds, J. W. (1968) Autoradiographic study of histogenesis in the mouse olfactory bulb. I. Time of origin of neurons and neuroglia. J. Comp. Neurol. 134: 287-304.

Hitchcock, P. F., T. L. Hickey, and C. G. Dunkel (1984) Genesis of morphologically identified neurons in the dorsal lateral geniculate nucleus of the cat. J. Comp. Neurol. 228: 200-209.

Hökfelt, T., and $\AA$. Ljungdahl (1972) Autoradiographic identification of cerebral and cerebellar cortical neurons accumulating labeled gamma-aminobutyric acid ( $\left.{ }^{3} \mathrm{H}-\mathrm{GABA}\right)$. Exp. Brain Res. 14: 354-362.

Hubel, D. H., and T. N. Wiesel (1963) Receptive fields of cells in striate cortex of very young, visually inexperienced kittens. J. Neurophysiol. 26: 994-1002.

Iversen, L. L., J. F. Mitchell, and V. Srinivasan (1971) The release of $\gamma$-aminobutyric acid during inhibition in the cat visual cortex. $\mathbf{J}$. Physiol. (Lond.) 212: 519-534.

Jackson, C. A. (1986) The genesis and development of the visual cortex in the ferret (Mustela putorius furo). Ph.D. thesis, University of Alabama at Birmingham, Birmingham, AL.

Jackson, C. A., J. D. Peduzzi, and T. L. Hickey (1984) Genesis of visual cortical neurons in the ferret. Soc. Neurosci. Abstr. 10:519.

Kisvárday, Z. F., A. Cowey, A. J. Hodgson, and P. Somogyi (1986) The relationship between GABA immunoreactivity and labelling by local uptake of $\left[{ }^{3} \mathrm{H}\right] \mathrm{GABA}$ in the striate cortex of monkey. Exp. Brain Res. 62: 89-98.

Krnjevíc, K., and S. Schwartz (1967) The action of $\gamma$-aminobutyric acid on cortical neurones. Exp. Brain Res. 3: 320-336.

Lund, J. S., R. D. Lund, A. E. Hendrickson, A. H. Bunt, and A. F. Fuchs (1975) The origin of efferent pathways from the primary visual cortex, area 17 , of the macaque monkey as shown by retrograde transport of horseradish peroxidase. J. Comp. Neurol. 164: 287-304.

Lund, J. S., R. G. Boothe, and R. D. Lund (1977) Development of neurons in the visual cortex (area 17) of the monkey (Macaca nemestrina): A Golgi study from fetal day 127 to postnatal maturity. J. Comp. Neurol. 176: 149-188.

Luskin, M. B., and C. J. Shatz (1985a) Neurogenesis of the cat's primary visual cortex. J. Comp. Neurol. 242: 611-631.

Luskin, M. B., and C. J. Shatz (1985b) Studies of the earliest generated cells of the cat's visual cortex: Cogeneration of subplate and marginal zones. J. Neurosci. 5: 1062-1075.

Maley, B., and B. W. Newton (1985) Immunohistochemistry of $\gamma$ aminobutyric acid in the cat nucleus tractus solitarius. Brain Res. 330: 364-368.

Marin-Padilla, M. (1971) Early prenatal ontogenesis of the cerebral cortex (neocortex) of the cat (Felis domestica). A Golgi study. I. The 
primordial neocortical organization. Anat. Embryol. (Berl.) 134: 117145.

Martin, K. A. C., P. Somogyi, and D. Whitteridge (1983) Physiological and morphological properties of identified basket cells in the cat's visual cortex. Exp. Brain Res. 50: 193-200.

McAllister, J. P. II, and G. D. Das (1977) Neurogenesis in the epithalamus, dorsal thalamus and ventral thalamus of the rat: An autoradiographic and cytological study. J. Comp. Neurol. 172:647-686.

Meyer, G., and R. Ferres-Torres (1984) Postnatal maturation of nonpyramidal neurons in the visual cortex of the cat. J. Comp. Neurol. 228: 226-244.

Miller, M. W. (1985) Cogeneration of retrogradely labeled corticocortical projection and GABA-immunoreactive local circuit neurons in cerebral cortex. Dev. Brain Res. 23: 187-192.

Montero, V. M., and J. Zempel (1985) Evidence for two types of GABA-containing interneurons in the A-laminae of the cat lateral geniculate nucleus: A double-label HRP and GABA-immunocytochemical study. Exp. Brain Res. 60: 603-609.

Parnavelas, J. G., R. Bradford, E. J. Mounty, and A. R. Lieberman (1978) The development of non-pyramidal neurons in the visual cortex of the rat. Anat. Embryol. (Berl.) 155: 1-14.

Peduzzi, J. D. (1986) Genesis of GABA immunoreactive neurons in the ferret visual cortex. Soc. Neurosci. Abstr. 12: 1372.

Peduzzi, J. D., and T. L. Hickey (1985) Birthdates of immunoreactive neurons in the ferret visual cortex. Soc. Neurosci. Abstr. 11: 806.

Rakic, P. (1974) Neurons in rhesus monkey visual cortex: Systematic relation between time of origin and eventual disposition. Science 183: $425-427$.

Reiffenstein, R. J., and M. J. Neal (1974) Uptake, storage, and release of $\gamma$-aminobutyric acid in normal and chronically denervated cat cerebral cortex. Can. J. Physiol. Pharmacol. 52: 286-290.

Ribak, C. E. (1978) Aspinous and sparsely-spinous stellate neurons in the visual cortex of rats contain glutamic acid decarboxylase. J. Neurocytol. 7: 461-478.

Ribak, C. E., J. E. Vaughn, and R. P. Barber (1981) Immunocytochemical localization of GABAergic neurones at the electron microscopical level. Histochem. J. 13: 555-582.

Ribak, C. E., L. Seress, G. M. Peterson, K. B. Seroogy, J. H. Fallon, and L. C. Schmucd (1986) A GABAcrgic inhibitory component within the hippocampal commissural pathway. J. Neurosci. 6:34923498.

Rogers, A. W. (1979) Techniques of Autoradiography, Elsevier/NorthHolland, New York.

Rose, D., and C. Blakemore (1974) Effects of bicuculline on functions of inhibition in visual cortex. Nature 249: 375-377.

Segraves, M. A., and A. C. Rosenquist (1982) The distribution of the cells of origin of callosal projections in cat visual cortex. J. Neurosci. 2: 1079-1089.

Shimada, M., and J. Langman (1970) Cell proliferation, migration and differentiation in the cerebral cortex of the golden hamster. J. Comp. Neurol. 139: 227-244.

Siegel, S. (1956) Nonparametric Statistics for the Behavioral Sciences, McGraw-Hill, Ncw York.

Sillito, A. M. (1979) Inhibitory mechanisms influencing complex cell orientation selectivity and their modification at high resting discharge levels. J. Physiol. (Lond.) 289: 33-53.
Sokal, R. R., and F. J. Rohlf (1981) Biometry: The Principles and Practice of Statistics in Biological Research, 2nd Ed., W. H. Freeman, San Francisco.

Somogyi, P. (1986) Seven distinct types of GABA-immunoreactive neurons in the visual cortex of cat. Soc. Neurosci. Abstr. 12: 583.

Somogyi, P., and A. J. Hodgson (1985) Antisera to $\gamma$-aminobutyric acid. III. Demonstration of GABA in Golgi-impregnated neurons and in conventional electron microscopic sections of cat striate cortex. $\mathbf{J}$. Histochem. Cytochem. 33: 249-257.

Somogyi, P., T. F. Freund, N. Halász, and Z. F. Kisvárday (1981) Selectivity of neuronal $\left.{ }^{3} \mathrm{I} I\right] \mathrm{GABA}$ accumulation in the visual cortex as revealed by Golgi staining of the labeled neurons. Brain Res. 225: $431-436$

Somogyi, P., T. F. Freund, J.-Y. Wu, and A. D. Smith (1983) The section-Golgi impregnation procedure. 2 . Immunocytochemical demonstration of glutamate decarboxylase in Golgi-impregnated neurons and in their afferent synaptic boutons in the visual cortex of the cat. Neuroscience 9: 475-490.

Somogyi, P., A. Hodgson, A. D. Smith, M. G. Nunzi, A. Gorio, and J.-Y. Wu (1984) Different populations of GABAergic neurons in the visual cortex and hippocampus of cat contain somatostatin- or cholecystokinin-immunoreactive material. J. Neurosci. 4: 2590-2603.

Somogyi, P., T. F. Freund, A. J. Hodgson, J. Somogyi, D. Beroukas, and I. W. Chubb (1985) Identified axo-axonic cells are immunoreactive for GABA in the hippocampus and visual cortex of the cat. Brain Res. 332: 143-149.

Soriano, E., A. Cobas, and A. Fairén (1986) Asynchronism in the neurogenesis of GABAergic and non-GABAergic neurons in the mouse hippocampus. Dev. Brain Res. 30: 88-92.

Taber Pierce, E. (1967) Histogenesis of the dorsal and ventral cochlear nuclei in the mouse. An autoradiographic study. J. Comp. Neurol. 131: $27-54$

Tsumoto, T., and H. Sato (1985) GABAergic inhibition and orientation selectivity of neurons in the kitten visual cortex at the time of eye opening. Vision Res. 25: 383-388.

Tsumoto, T., W. Eckart, and O. D. Creutzfeldt (1979) Modification of orientation sensitivity of cat visual cortex neurons by removal of GABA-mediated inhibition. Exp. Brain Res. 34: 351-363.

Turncr, D. L., and C. L. Ccpko (1987) A common progenitor for neurons and glia persists in rat retina late in development. Nature 328: 131-136.

Ulmar, G., and V. Neuhoff (1980) Free amino acids in the isolated cortex of the rat determined by the Dns microassay. Exp. Neurol. 69: 99-109.

Wallingford, E., R. Ostdahl, P. Zarzecki, P. Kaufman, and G. Somjen (1973) Optical and pharamacological stimulation of visual cortex neurones. Nature (New Biol.) 242: 210-212.

Wässle, H., L. Peichl, and B. B. Boycott (1981) Dendritic territories of cat retinal ganglion cells. Nature 292: 344-345.

Wolff, J. R., B. M. Chronwall, and M. Rickmann (1978) Morphogenetic relations between cell migration and synaptogenesis in the neocortex of rat. In Proceedings of the European Society of Neurochemistry, V. Neuhoff, cd., pp. 158-173, Verlag Chemic, Ncw York. 